\title{
Sobre o artigo: "Fábrica da nutrição neoliberal: elementos para uma discussão sobre as novas abordagens comportamentais"
}

\author{
I ${ }^{1}$ Marcela Cristina Elias Villela, ${ }^{2}$ César Henrique de Carvalho Moraes, \\ ${ }^{3}$ Marle dos Santos Alvarenga I
}

\author{
1 Universidade Federal do Espirito Santo. Vitória-ES, Brasil (villelamarcela88@gmail.com). ORCID: 0000-0001-9845-3646 \\ 2 Universidade de São Paulo. São Paulo-SP, Brasil (cesar.moraes@usp.br). ORCID: 0000-0003-1108-8100 \\ ${ }^{3}$ Universidade de São Paulo. São Paulo-SP, Brasil (marlealvarenga@gmail.com). ORCID: 0000-0001-6922-2670 \\ Recebido em: 15/02/2021 \\ Aprovado em: 13/04/2021 \\ Revisado em: 11/10/2021
}

DOI: http://dx.doi.org/10.1590/S0103-73312021310401

Tradicionalmente pautada por diferentes vertentes de interesses, a máxima de que "todo homem tem garantidos os direitos à saúde e à vida" parece ser aceita por quase todas as sociedades modernas. Ainda que descontada alguma sobra de aforismo, a proposição marcha vívida e robusta em muitos discursos, muito embora ainda resista uma larga separação entre a retórica e a tibieza da prática cotidiana. Apesar das milhôes de mortes por falta de vacinas em diferentes partes do mundo, outros tantos milhôes de vidas são salvas anualmente, ao longo de décadas e de todo o globo, de doenças passíveis de prevenção vacinal (ORENSTEIN \& AHMED, 2017). Tratadas como direito basilar, as vacinas e a vacinação se misturam com o conceito mais abrangente de saúde pública.

$\mathrm{O}$ artigo citado afirma que a disputa entre diferentes modelos e a proliferação de abordagens comportamentais na área da alimentação e nutrição é problemática e as autoras assistem a isso "atônitas". Certamente, pensar o campo da nutrição no cenário atual e entendê-lo junto ao neoliberalismo é interessante, mas os exemplos adotados para esta discussão carecem de fundamentação nas associaçôes propostas.

Todo campo científico é e sempre será marcado por disputas, isso porque a ciência é reflexo de um processo social, permeada por relaçóes e interesses diversos 
- incluindo questôes financeiras, políticas e institucionais (Azevedo,2011). Além disso, cada conceito, teoria ou abordagem é a construção de uma verdade vista a partir de um prisma reduzido, parcial e sem neutralidade (Kuhn, 1998). Nesse sentido, as disputas são essenciais para contínua exploração do campo.

Foucault (2014) compreende os saberes como objetos de relaçôes de poder ou como dispositivo político; buscou verificar a singularidade dos acontecimentos de modo contextualizado contemplando as descontinuidades, os saberes desqualificados ou não legitimados "uma disciplina não é a soma de tudo o que pode ser dito de verdadeiro sobre alguma coisa...é feita de erros e verdades. Erros ... que têm funçóes positivas, uma eficácia histórica, um papel indissociável daquele das verdades" (p. 8-9).

Em resumo, o conhecimento é usado para controlar e definir o poder. E na nutrição o paradigma estabelecido é biomédico, o qual tem uma compreensão limitada sobre a alimentação e o comer. A ineficiência e decadência desse modelo é uma questão já posta por diversos pares, não referenciamos aqui por limite de palavras, também chamada de crise no paradigma. Portanto em vista de um modelo fracassado, há urgência na busca por soluções que possam melhor responder às demandas contemporâneas.

Essa breve exploração sobre a circulação do poder é fundamental, afinal o "discurso que ordena a sociedade é sempre o discurso daquele que detém o conhecimento. $\mathrm{Na}$ sociedade contemporânea ocidental, a verdade é centrada na forma do discurso científico" (Kraemer et al, 2014 p. 1346). É vital a contínua busca dos pesquisadores de diversos campos para a compreensão, resolução ou amortização dos sofrimentos humanos - dentre eles aqueles relacionados ao comer, a comida e ao corpo. E, de acordo com a própria história do conhecimento, continuará havendo conflitos e divergências, mas cabe a todos o exercício do pensamento crítico e esforço para avançar as fronteiras (de)limitadas das disciplinas.

A ciência que estuda o comportamento alimentar, ainda que jovem, está orientada por pesquisas cientificas e náo por modismos, esses sim ancorados em soluçôes mágicas e simplistas. As abordagens que tentam compreender e manejar o comportamento alimentar, buscam por perspectivas menos fragmentadas na tentativa de construir pontes com outras áreas como a: antropologia, sociologia, filosofia, psicologia e todos as disciplinas que se aproximam para entender os seres humanos. 
Especificamente sobre a psicologia, as autoras mencionam que se propóe a "traçar um panorama" o que absolutamente não é feito. A forma de compreender o comportamento é parcial, e a concepção do behaviorismo é desatualizada e equivocada. A perspectiva multicausal de Skinner, de raiz, entende que a interação compreende tudo: os comportamentos privados (pensar, sentir etc.) bem como o aspecto sociocultural. Portanto não há sustentação para o panorama que se propõe (Baum, 2007; Chiesa, 1994).

O comportamento, em suma, é um grande evento composto por aquilo que vem antes da resposta comportamental e aquilo que vem depois e, a depender do entrelaçamento destes componentes, se dá o aprendizado. Além disso, a seleção dos comportamentos que permanecem e daqueles que diminuem de frequência depende, necessariamente, de aspectos ligados a espécie - a filogênese; do aprendizado que se estabelece em vida - a ontogênese; e da cultura que perpassa todos os anteriores. É improcedente a problemática do ensaio a este respeito, dado que as teorias apontadas como insuficientes guardam em seu cerne essa consideração biopsicossociocultural do comportamento. Ressaltamos ainda que há na crítica comportamento versus hábito a fragilidade de não se considerar que o mesmo fenômeno comportamental pode ser concebido por diferentes perspectivas, a depender do ponto de partida que se adote (Hogan, 2015).

Destacamos ainda como inadequada a afirmação de que tais "técnicas" (re) colocam na agenda estratégias centradas na responsabilização do indivíduo e no autocontrole. Falta ao artigo maior contextualização da nutriçâao como ciência e profissão, e compreensão dos conceitos controle e cuidado de si.

O paradigma herdado e oriundo da Medicina tem toda sua estruturaçáo baseada no controle - de corpos, discursos, práticas e saberes, de modo que desde a formação o nutricionista é treinado para promover a docilização e com isso destitui os pacientes de sua subjetividade. Isso pode ser observado amplamente no olhar voltado para a patogênese em detrimento da pessoa que adoece; na redução aos aspectos biológicos; nas prescriçóes impositivas padronizadas em comportamentos e necessidades; no diálogo hierárquico, entre outras condutas opressoras que tentam de alguma maneira exercer o biopoder (Kraemer et al, 2014).

Em oposição ao controle, as abordagens inseridas no campo comportamental buscam uma aproximação de um modelo que se baseia no cuidado. Essa perspectiva pode ser observada pela ampliação da compreensão dos indivíduos para além das 
questôes biológicas clássicas; promoção da autonomia; co-construção de um plano que se orienta conforme desejos, necessidades e valores de cada pessoa (inclusive considerando ela viver o risco); estabelecimento de um relacionamento com forte aliança terapêutica baseada na escuta e na comunicaçâo não violenta de modo a contribuir com o desenvolvimento de habilidades, competências e estratégias a fim de promover uma vida valorosa, vista sob a ótica Foucaultiana como obra de arte. Em suma, a autonomia é a o ponto de partida para que cada pessoa possa trilhar seu caminho, e ao nutricionista, cabe o exercício da parceria e fortalecimento para que o paciente possa cuidar de si.

Ainda, o limite de palavras desta carta não nos permite evoluir as colocaçóes equivocadas sobre Mindful Eating (ME), comer intuitivo (CI) e Nutrição Comportamental (NC) - hora denominadas técnicas, hora abordagem, sem definição e referências corretas e com contradiçóes. Ainda mais apontar seu surgimento como um problema é leviano. Há vários estudos apontando a eficácia e benefícios do comer intuitivo e abordagens baseadas em mindfulness - que não são citados. Falácia, portanto, é criticá-los sem aprofundamento - não são "supostas evidências" e sim estudos de intervenção e não opinativos.

Tudo em nosso "mundo neoliberal" pode ser distorcido, vítima de marketing apenas, e divulgado amplamente de forma irresponsável. Colocar no mesmo "balaio" teorias comportamentais, religiōes orientais e técnicas motivacionais só confunde ao invés de esclarecer o momento atual. E o desejo que é colocado no final como objeto de resgate é trabalhado tanto pelo ME, CI e NC - por aqueles que estudaram seriamente os mesmos e os utilizam de forma responsável. Como em tudo, a responsabilidade e a ética fazem toda diferença.

Segundo Kuhn (1998), somente quando os cientistas analisam criticamente seus fundamentos teóricos, conceituais, metodológicos e instrumentais, é que podem concentrar esforços nos problemas de pesquisa enfrentados no seu tempo. $\mathrm{O}$ paradigma da Nutrição se estabeleceu dentro de um contexto o qual já não é mais uma realidade, concentrou seus esforços para resolver questóes da época e mobilizou conhecimentos que estavam disponíveis. Entretanto, hoje segundo a classificação autor, vivemos uma fase de crise. E assim, é natural a emergência de novas teorias, as quais são precedidas de algumas inseguranças, visto que precisa haver uma (re) construção do que estava estabelecido como verdade única. E mesmo diante de diversos problemas e anomalias derivados desse paradigma biologicista clássico, ele 
ainda não foi refutado e não será enquanto não houver uma alternativa aceita e defendia pelos membros da comunidade científica.

Não é possível mais tentarmos ajustar as anomalias presentes ao paradigma. Precisamos mesmo repensar a reforma e reformar o pensamento. Nesse sentido, éainda mais interessante a visão limitada proposta pelo artigo - de verdade ancorada apenas pela ótica da psicanálise e ainda parcialmente explorada. No entanto, vale destacar que as terapias comportamentais de segunda e terceira geração, cientificamente, são as que apresentam melhor capacidade de serem estruturadas, pesquisadas, replicadas e consequentemente comprovadas. $\mathrm{E}$ isso não tira o mérito de todas as outras abordagens terapêuticas, mas para a ciência baseada em evidências selvagem é basear as condutas profissionais em achismos, opiniōes e experiências pessoais.

\section{Referências}

AZEVEDO, E. Riscos e controvérsias na construção social do conceito de alimento saudável: o caso da soja. Rev. Saúde Pública, 2011; 45(4): 781-718.

KUHN, T. A estrutura das revoluçōes científicas. Editora Perspectiva, 5 ed. São Paulo, 1998.

FOUCAULT, M. Vigiar e punir: nascimento da prisäo. 42.ed. Petrópolis: Vozes, 2014.

KRAEMER, F. et al. O discurso sobre alimentação saudável como estratégia de biopoder. Rev. Saúde Coletiva, Rio de Janeiro, 24 [4]: 1337 - 1359, 2014.

Baum WM. Compreender o behaviorismo: comportamento, cultura e evolução. Trad. Maria Teresa Araujo Silva. 2nd ed. Porto Alegre: Artmed; 2007.

Chiesa M. Radical Behaviorism: The Philosophy and the Science. Boston: Authors Cooperative, Inc., Publishers; 1994.

Hogan JA. A framework for the study of behavior. Behav Processes [Internet]. 2015;117:105-13. 


\section{ERRATA}

No comentário sobre o artigo "FÁBRICA DA NUTRIÇÃO NEOLIBERAL: ELEMENTOS PARA UMA DISCUSSÃO SOBRE AS NOVAS ABORDAGENS COMPORTAMENTAIS", com número de DOI: http://dx.doi.org/10.1590/ S0103-73312021310401 publicado no periódico Physis: Revista de Saúde Coletiva, v. 31, n. 4, e310401, na página 1, erro de nome dos autores:

ONDE SE LÊ:

Marcela Cristina Villela

Cesar Henrique Moraes

Marle os Santos Alvarenga

LEIA-SE:

Marcela Cristina Elias Villela

César Henrique de Carvalho Moraes

Marle dos Santos Alvarenga 